\title{
Global Health: A Review of Concepts, Players, and Publications
}

\author{
Fabio Zicker ${ }^{1 *}$, Bruna Fonseca ${ }^{1}$, Priscila Albuquerque ${ }^{1}$ \\ ${ }^{1}$ Center for Technological Development in Health (CDTS), National Institute of Science and Technology of Innovation on \\ Diseases of Neglected Populations (INCT-IDPN), Oswaldo Cruz Foundation (Fiocruz), Brazil \\ Corresponding Author: Fabio Zicker, PhD, Professor, Center for Technological Development in Health (CDTS), National \\ Institute of Science and Technology of Innovation on Diseases of Neglected Populations (INCT-IDPN), Oswaldo Cruz \\ Foundation (Fiocruz), Brazil. Tel: +55-21999043400, Email: fabio.zicker@gmail.com
}

Received October 13, 2018; Accepted February 21, 2019; Online Published March 3, 2019

\begin{abstract}
Introduction: The increasing number of global health initiatives have contributed to improving access to health services and building knowledge platforms. However, the distribution of activities and knowledge produced has been uneven. To scope the scientific output in global health, publications from 2008-2017 were reviewed to identify major players, assess the extent of involvement of low- and middleincome countries (LMIC), and map areas of research interest.

Methods: A total of 3153 Web of Science (WoS) publications were retrieved, of which 2423 were selected for this review. The country of origin, institutions involved, types of documents, language of publication, journal titles, content categories, authorship, themes, and characteristics of collaboration were examined.

Results: Over the years, the number of global health publications from both high-income countries (HIC) and LMIC has increased. Authors from LMIC were engaged in $19.3 \%$ of the publications, representing $10.3 \%$ of first authors and $9.7 \%$ of single-author articles. Collaboration across World Health Organization (WHO) regions ranged from $29.6 \%$ to $64.6 \%$. Themes of greatest research interest were capacity development, health policy and systems, and disease control.

Conclusion: Global health research is experiencing rapid expansion, but LMIC authors continue to have limited involvement. The current study revealed diversity in publications, journals, and actors with a marked influence from developed countries. As north-south and southsouth research partnerships are increasing across the world, it is important to ensure open collaboration between partners and alignment with public health research priorities and needs.
\end{abstract}

Keywords: Global Health, Research Collaboration, Research Networks, Bibliometric Review, Scoping Review

Citation: Zicker F, Fonseca B, Albuquerque P. Global health: a review of concepts, players, and publications . Int J Travel Med Glob Health 2019;7(1):4-9. doi:10.15171/ijtmgh.2019.02.

\section{Introduction}

The interest in global health has expanded considerably in the last decades. Traditional and new actors have engaged in a range of initiatives including research and development (R\&D), training, program implementation, and policy development. The goal is to contribute to reducing the burden of diseases that disproportionally affect low- and middleincome countries (LMIC). The global health scenario has evolved to encompass a multitude of organizations, strategies, and approaches that have offered new opportunities for the collaboration and engagement of LMIC in decision-making and management. ${ }^{1}$ Multilateral, regional, and bilateral cooperation has focused on improving the capacity to prevent, control, or eliminate diseases and unfavorable health conditions.
Some public-private partnerships have been established with international resources to increase access to health technologies and to develop new drugs, vaccines, and diagnostics for neglected diseases., ${ }^{2,3}$ Non-state actors such as philanthropic foundations, NGOs, and multinational corporations have substantially increased funding and donations to product R\&D. ${ }^{4}$

Demographics and disease transitions, the health of migrating populations, and wealth inequalities are emerging challenges to global health. The United Nations' Millennium Development Goals (MDGs) and the Sustainable Development Goals (SDGs) have provided the impetus, direction, and target for this dynamic movement. ${ }^{5}$ The World Health Organization (WHO) has reinforced its role in providing technical cooperation for the development and

Copyright $(\subset) 2019$ The Author(s). This is an open-access article distributed under the terms of the Creative Commons Attribution License (http:// creativecommons.org/licenses/by/4.0), which permits unrestricted use, distribution, and reproduction in any medium, provided the original work is properly cited. 
strengthening of national health research systems and for the use of evidence in policy-making and advocating the principle of universal health coverage. ${ }^{6}$

An increasing number of scientific articles and discussion papers have addressed different perspectives of global health, such as health services delivery, health economics, social determinants of health, and capacity development and equity in health, among others. However, there is fragmentation and even an overlap in the knowledge produced through international collaboration and no clear picture of the role and engagement of LMIC in setting priorities.

This article aimed to provide an overview of the field and actors in the global health arena through the analysis of publications indexed in the Web of Science (WoS) in the last 10 years. The review mapped authors, journals, institutions, countries and their connections and identified themes of more interest. The article further attempted to offer a perspective of the context in which global health knowledge is produced to inform researchers, health officials, and policymakers.

\section{Who Is Publishing in Global Health?}

\section{Methods}

Data on scientific publications was retrieved from the bibliometric database WoS filtering for articles containing the expression "global health" in the title and/or abstract during the period 2008-2017. The timeframe established intended to capture the more recent trend in the field. WoS is a structured database covering a large number of healthrelated academic journals. It provides complete information about authorship and content allowing different types of analysis. The data was imported into the data/text mining software VantagePoint (Search Technology Inc.) for cleaning, harmonization, removal of ambiguity, and analysis. The geographical distribution, types of documents, language of publication, WoS pre-defined categories, journals, and institutions involved were described.

\section{Results}

From a total of 3153 records on global health extracted, 2423 were selected, corresponding to original research articles $(n=1229)$, editorials $(n=1042)$ and reviews $(n=152)$. The remaining publications (reports of meetings, abstracts, book appraisals, letters, news, proceedings, and bibliographical material) were not included in the analysis. While academic articles accounted for $39 \%$ of the WoS records, one-third of the records were editorials, revealing to some extent that global health has been a topic of growing interest and discussion. There was a significant increase in the number of publications from high-income countries (HIC) and LMIC over the years (Figure 1). A total of 121 countries were involved in the 2,423 publications. USA investigators co-authored $53.1 \%$ of publications, followed by the UK (18.0\%), Canada (11.3\%), Switzerland (5.8\%) and Australia (5.0\%). Authors from these five countries together accounted for $88.2 \%$ of all publications indexed. Two sub-Saharan African countries (Kenya and Uganda) and the countries of the group denominated BRICS (Brazil, India, China, and South Africa) were among the top 20 countries publishing on global health (Table 1). One-third

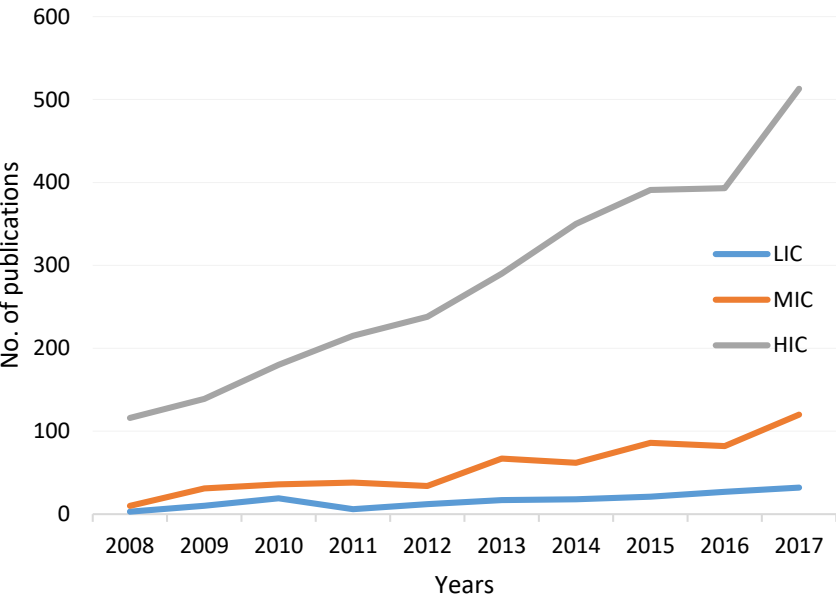

Figure 1. Number of Global Health publications from high-, middle-, and low-income countries.

Table 1. Number of Co-authorships by Country ${ }^{a}$

\begin{tabular}{|c|c|c|c|}
\hline Rank & $\begin{array}{c}\text { Countries } \\
\text { (out of 121) }\end{array}$ & $\begin{array}{c}\text { Number of } \\
\text { Co-authorships }\end{array}$ & Percent \\
\hline 1 & USA & 1286 & 53.1 \\
\hline 2 & UK & 436 & 18.0 \\
\hline 3 & Canada & 273 & 11.3 \\
\hline 4 & Switzerland & 140 & 5.8 \\
\hline 5 & Australia & 120 & 5.0 \\
\hline 6 & South Africa & 73 & 3.0 \\
\hline 7 & China & 70 & 2.9 \\
\hline 8 & Germany & 70 & 2.9 \\
\hline 9 & India & 58 & 2,4 \\
\hline 10 & Brazil & 55 & 2.3 \\
\hline 11 & Sweden & 53 & 2.2 \\
\hline 12 & France & 51 & 2.1 \\
\hline 13 & Norway & 51 & 2.1 \\
\hline 14 & Uganda & 41 & 1.7 \\
\hline 15 & Belgium & 37 & 1.5 \\
\hline 16 & Japan & 33 & 1.4 \\
\hline 17 & Netherlands & 31 & 1.3 \\
\hline 18 & Kenya & 30 & 1.2 \\
\hline 19 & Singapore & 25 & 1.0 \\
\hline 20 & Ireland & 20 & 0.8 \\
\hline
\end{tabular}

a The same publication may be counted for more than one country if their authors share the co-authorship.

b $\%$ in relation to the total number of publications $(n=2423)$.

of the publications (32.9\%) were single-authored, and $43 \%$ were co-authored internationally. Altogether, LMIC authors were engaged in $19.3 \%$ of the publications, representing $10.3 \%$ of first authors and $9.7 \%$ of the single author articles. There was a marked increase in the number of single-author publications, especially in editorials (Figure 2).

The publications involved 1,986 institutions, which reveals the wide interest in collaboration. Those academic institutions known for their engagement in global health research were more represented (Table 2). The publications were found in 742 journals, including traditional public health journals, and more recent titles focused on global health. The Lancet was the leading journal accounting for $7.4 \%$ of all published articles 


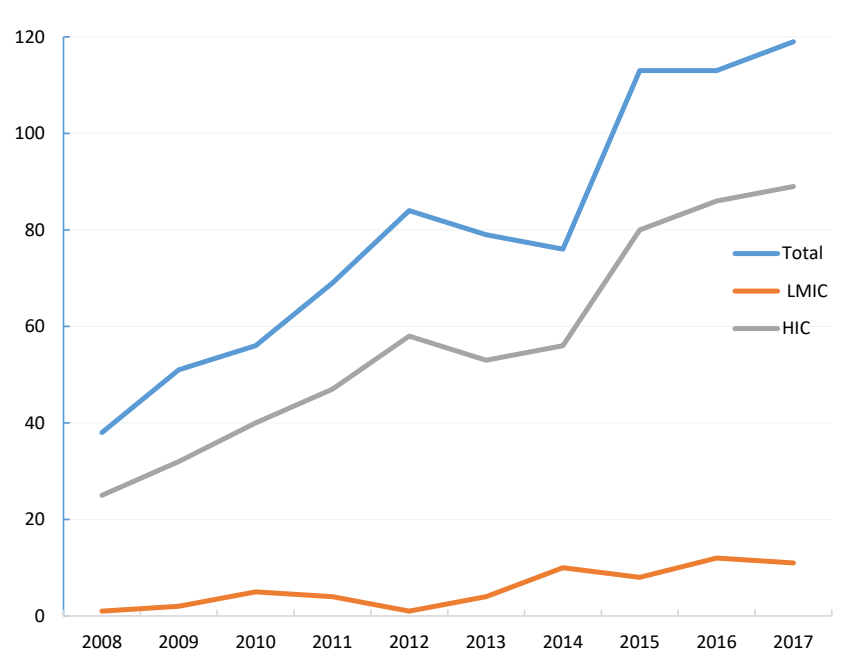

Figure 2. Number of Single-Author Articles Per Year by Country Income Group.

Table 2. Institutions with the highest number of co-authorships ${ }^{\text {a }}$

\begin{tabular}{|c|c|c|c|}
\hline Rank & Institutions & $\begin{array}{c}\text { No. of Publications } \\
\text { (out of 1986) }\end{array}$ & $\%^{\mathrm{b}}$ \\
\hline 1 & Harvard University & 166 & 6.9 \\
\hline 2 & University of Toronto & 128 & 5.3 \\
\hline 3 & London School of Hyg. \& Trop Med & 112 & 4.6 \\
\hline 4 & University of California & 112 & 4.6 \\
\hline 5 & University of Washington & 93 & 3.8 \\
\hline 6 & Johns Hopkins University & 81 & 3.3 \\
\hline 7 & World Health Organization & 72 & 3.0 \\
\hline 8 & Georgetown University & 69 & 2.8 \\
\hline 9 & Pennsylvania University & 57 & 2.4 \\
\hline 10 & Oxford University & 55 & 2.3 \\
\hline 11 & Brigham \& Women's Hospital & 52 & 2.1 \\
\hline 12 & University College London & 48 & 2.0 \\
\hline 13 & Yale University & 48 & 2.0 \\
\hline 14 & Mass General Hospital & 47 & 2.0 \\
\hline 15 & University of Edinburgh & 47 & 1.9 \\
\hline 16 & Kings College London & 46 & 1.9 \\
\hline 17 & McGill University & 46 & 1.9 \\
\hline 18 & Emory University & 45 & 1.9 \\
\hline 19 & Duke University & 44 & 1.8 \\
\hline 20 & Stanford University & 41 & 1.7 \\
\hline
\end{tabular}

${ }^{a}$ The same publication may be counted for more than one institution.

b $\%$ in relation to total number of global health publications $(n=2423)$.

and editorials on global health (Table 3). The publications were in nine different languages, but only $2.5 \%$ of them were in a language other than English. In frequency order, these were French, Spanish, German, Norwegian, Portuguese, Italian, Japanese, and Korean. The automatic WoS classification by areas of knowledge was not useful. There was a large overlap of categories, and the same article could have been classified in different ways.

\section{Profile of Research Collaboration and Thematic Areas Methods}

The open-source software Gephi ${ }^{8}$ was used for visualization and statistical analysis of international research networks formed by linking the published authors. The VOSviewer software $^{9}$ was used to generate maps and clusters of research terms estimating an "association strength" based on the number of co-occurrences of research terms. ${ }^{10}$ Terms that co-occurred frequently in the same publications were automatically positioned close to each other in the mapping, while weakly related terms were positioned further away.

\section{Results}

Figure 3 shows the pattern of global research collaboration for the top 5 countries with more international links based on the authors' affiliations. Two countries are considered connected if their researchers shared the authorship of a paper. The thickness of the links indicates the frequency of collaboration between the two countries. Table 4 shows the frequency of collaborative research within and between WHO regions. Although all articles refer to global health issues with a focus on LMIC, the co-authorship pattern was predominately within a single WHO region rather than across regions. Interregional research collaboration ranged from $29.6 \%$ (Americas) to 64.6\% (Eastern Mediterranean countries).

Based on the maps and clusters of related terms, it was possible to consolidate broad themes of interest. Analysis showed three major subject areas in the publications (Figure 4). It is possible to identify a cluster of terms associated with research capacity development mostly through training (in green), research policy and systems (in red), and diseaserelated terms (in blue).

Table 3. Number of Publications by Journal

\begin{tabular}{llcl}
\hline Rank & Journals (out of 742) & $\begin{array}{c}\text { No. of } \\
\text { publications }\end{array}$ & \%* \\
\hline 1 & The Lancet & 180 & 7.4 \\
\hline 2 & Global Health & 53 & 2.2 \\
\hline 3 & Global Public Health & 45 & 1.9 \\
\hline 4 & Annals of Global Health & 44 & 1.8 \\
\hline 5 & Global Health Action & 43 & 1.8 \\
\hline 6 & Amer. Journal of Trop. Med. \& Hygiene & 40 & 1.7 \\
\hline 7 & Academic Medicine & 39 & 1.6 \\
\hline 8 & PLoS Medicine & 37 & 1.5 \\
\hline 9 & New England Journal of Medicine & 35 & 1.4 \\
\hline 10 & Lancet Global Health & 32 & 1.3 \\
\hline 11 & Journal of Law, Medicine \& Ethics & 30 & 1.2 \\
\hline 12 & Health Policy Planning & 28 & 1.2 \\
\hline 13 & Bulletin of the World Health Organization & 25 & 1.0 \\
\hline 14 & International Health Policy Management. & 25 & 1.0 \\
\hline 15 & Journal of the American Medical Assoc. & 24 & 1.0 \\
\hline 16 & Infectious Dis. Clinics of North America & 23 & 0.9 \\
\hline 17 & BMC Medical Education & 20 & 0.8 \\
\hline 18 & Global Health Promotion & 20 & 0.8 \\
\hline 19 & Journal of Global Health & 18 & 0.7 \\
\hline 20 & Military Medicine & 18 & 0.7 \\
\hline$* \%$ in relation to 2423 publications. & & \\
\hline
\end{tabular}

*\% in relation to 2423 publications. 


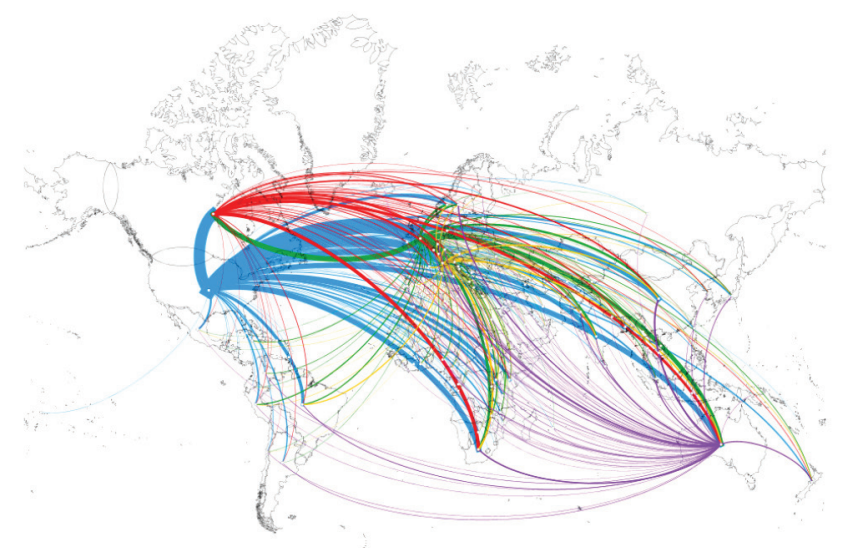

Figure 3. Map of Research Collaboration for the 5 Countries With Most Authorship Links.

\section{Discussion}

The concept and scope of what has been called "global health" have been debated. ${ }^{11}$ The understanding that "global health is public health for the public good" is based on the need to address determinants of health at national and global levels. ${ }^{12}$ The short definition "collaborative trans-national research and action for promoting health for all" suggests that research should contribute to public health activities. ${ }^{13}$ This has been the focus of the WHO's work with member states promoting activities, processes, and capacity development for the use of research evidence in public health decision-making and action. $^{14}$

Global health has become commonly associated with many disciplines. It has been considered a component of foreign policy and a major philanthropic target. ${ }^{15}$ The concepts and actions under the labels "global health diplomacy" and "global health governance" have progressively been adopted by countries under the stewardship of international organizations. They involve the understanding, engagement, negotiation, and organizational aspects of dealing with public health issues requiring multinational approaches and coordination.

The international legislation, epidemiological risks, and operational aspects of public health can have political, social, and economic implications beyond borders. Global health security is a typical example in this area. It relates to the efforts required by countries, international organizations,

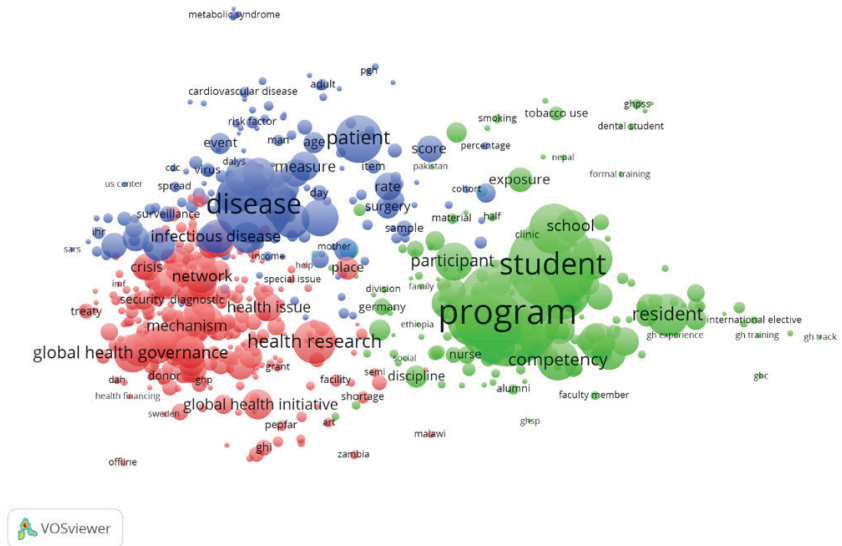

Figure 4. Thematic Map With 3 Color-Coded Clusters of Related Terms. The diameter and label sizes are proportional to the term occurrence in the publications.

communities, and NGOs to increase capacity to prevent, control, and eliminate infectious diseases that can spread internationally. ${ }^{15}$ The recent outbreaks of Ebola in West Africa and Zika in Brazil have highlighted the importance of international cooperation and health system preparedness to respond to such events. ${ }^{16}$

The increasing number of global health initiatives (GHI) has raised concerns regarding their coherence and synergy. An analysis of twenty-six well-established initiatives showed that even though they have diverse objectives and operational aspects, there is room for collaboration and the integration of activities. $^{1}$

The production of local knowledge is essential to the improvement of global health. Results of the current study revealed that developed countries play a leading role in knowledge production, while most of the global health issues to be addressed - equity in access, good quality of services, and affordability - are typical of LMIC. The rising trend of research collaboration over time was noticeable based on networks and the engagement of institutions and countries, particularly LMIC. This is an indication of the relevance of the themes and demonstrates the commitment of developed and developing countries to tackling public health priority issues of developing countries. The importance of a broad engagement of LMIC researchers and stakeholders in developing a more equitable global research agenda has been exemplified for neglected tropical diseases of poverty. ${ }^{17}$

Table 4. Collaborative Publications (\%) Within and Between WHO Regions ${ }^{a}$

\begin{tabular}{llllllll}
\hline & AMR & EUR & WPR & AFR & SEAR & EMR \\
\hline AMR & 70.4 & 20.7 & 22.3 & 28.2 & 17.9 & 15.2 & 18.9 \\
EUR & 12.4 & 60.3 & 15.7 & 48.3 & 6.0 & 9.5 & 13.4 \\
WPR & 5.5 & 6.4 & 6.6 & 40.5 & 4.8 & 3.6 & 3.6 \\
AFR & 7.7 & 8.1 & 3.2 & 2.5 & 2.7 & 4.5 & 9.4 \\
SEAR & 3.0 & 1.3 & & & 35.4 \\
\hline EMR & 1.1 & &
\end{tabular}

a Based on the authorship of 2423 global health publications. 
The WHO has proposed essential areas for promoting evidence-based actions in global health. Most of them are of a structuring nature, including the strengthening of national and international health information systems and health indicators; the establishment of national health research systems and priority setting; and increasing the capacity of countries for developing evidence-informed policies. ${ }^{14}$

\section{Summary of Evidence}

A review of the WoS records of publications gave an insight into the major players and the direction of collaboration. Overall, there is a growing number of organizations engaged, and the significant scientific contributions that have come from high-income and upper-middle income countries are associated with a greater number of researchers and institutions from LMIC. International cooperation tended to be within geographical regions, but there is an important flow of collaboration between investigators from HIC and LMIC. The clusters of themes revealed broad areas of interest in the scientific community. Themes included (i) research capacity building, a key area of interest to many international development agencies. ${ }^{18}$ The goal is to develop human resources and institutional capacity for effective research targeted at key priorities; (ii) global health governance and strengthening national health research systems, a primary interest of the Council on Health Research for Development (COHRED); ${ }^{19,20}$ (iii) new strategies and action networks for disease control, which have received the support of academic organizations, international partnerships, and the WHO. ${ }^{21,22}$ Embedding research into health policy and practice has become the key objective of several GHI. ${ }^{23}$ Based on the thematic analysis, the current study showed an increasing interest in implementation research, an area that aims at bringing new strategies and interventions to practice by understanding barriers and facilitators of program implementation.

\section{Conclusion}

The current study highlighted that global health literature has expanded considerably in the last decade with a marked influence by researchers from developed countries, even though critical health issues are of particular interest to LMIC. As research partnerships are growing across the world, it is important to ensure that fair collaboration is established between unequal partners. ${ }^{24}$ The impact of the overall investment in capacity development and knowledge production in global health and its actual influence on the research profile of and public health conditions in LMIC deserve careful attention.

\section{Limitations}

The current article was structured following the 2018 PRISMA extension checklist for scoping reviews. The authors acknowledge that the search strategy used to retrieved publications and the inclusion criteria adopted may have missed a small proportion of records. However, considering the proposed focus, the authors believe that the study material was a good representation of reality. The use of network

\section{Review Highlights}

\section{What Is Already Known?}

Global health scientific literature has expanded considerably in the last decade with a marked influence from authors in developed country, even though critical health issues are of particular interest to LMIC.

\section{What This Study Adds?}

Thematic analysis revealed a particular interest in research capacity building, research on health policy and systems, and networks and strategies for disease control.

analysis and thematic clustering to map global health research activities proved to be useful in identifying trends, central organizations, and research subjects of greater interest.

\section{Authors' Contributions}

FZ was responsible for the study concept and first draft of the manuscript. PA was responsible for data collection and analysis. FZ, BF, and PA were responsible for data interpretation and the final editing of the manuscript.

\section{Conflict of Interest Disclosures}

The authors declare that they have no conflicts of interest.

\section{Ethical Approval}

The current study did not require ethical review.

\section{Funding/Support}

This work was supported by the Brazilian National Counsel of Technological and Scientific Development (CNPq), grants \# 458100/2014-15 and 440231/2015-9 and National Institute of Science and Technology of Innovation on Diseases of Neglected Populations (INCT-IDPN).

\section{References}

1. Zicker F, Faid M, Reeder J, Aslanyan G. Building coherence and synergy among global health initiatives. Health Res Policy Syst. 2015;13:75. doi:10.1186/s12961-015-0062-3.

2. Reddy D, Spigelman M. Product development partnerships: an innovative approach to tackling neglected diseases. Devpolicy website. http://devpolicy.org/product-developmentpartnerships-an-innovative-approach-to-tackling-neglecteddiseases-20140528/. Published 2014.

3. Policy Cures, G-Finder. Neglected disease research and development: a five-year review. Policy Cures \& London International Development Centre; 2012. http://www.policycures. org/downloads/GF2012_Report.pdf.

4. Viergever RF, Hendriks TCC. The 10 largest public and philanthropic funders of health research in the world: what they fund and how they distribute their funds. Health Res Policy Syst. 2016;14(1):12. doi:10.1186/s12961-015-0074-z.

5. United Nations. Sustainable Development Goals Funds - From MDGs to SDGs. http://www.sdgfund.org/mdgs-sdgs.

6. World Health Organization (WHO). The world health report: health systems financing: the path to universal coverage: executive summary. Geneva: WHO; 2010.

7. Ottersen OP, Dasgupta J, Blouin C, et al. The political origins of health inequity: prospects for change. Lancet. 2014;383(9917):630- 
667. doi:10.1016/s0140-6736(13)62407-1.

8. Bastian M, Heymann S, Jacomy M. Gephi: an open source software for exploring and manipulating networks. Proceedings of the Third International AAAI Conference on Web and Social Media; 2009. https://gephi.org/publications/gephi-bastian-feb09.pdf.

9. van Eck NJ, Waltman L. Software survey: VOSviewer, a computer program for bibliometric mapping. Scientometrics. 2010;84(2):523538. doi:10.1007/s11192-009-0146-3.

10. Waltman L, van Eck NJ, Noyons ECM. A unified approach to mapping and clustering of bibliometric networks. J Informetr. 2010;4(4):629-635. doi:10.1016/j.joi.2010.07.002.

11. Koplan JP, Bond TC, Merson MH, et al. Towards a common definition of global health. Lancet. 2009;373(9679):1993-1995. doi:10.1016/s0140-6736(09)60332-9.

12. Fried LP, Bentley ME, Buekens $P$, et al. Global health is public health. Lancet. 2010;375(9714):535-537. doi:10.1016/s01406736(10)60203-6.

13. Beaglehole R, Bonita R. What is global health? Glob Health Action. 2010;3. doi:10.3402/gha.v3i0.5142.

14. World Health Organization (WHO). EVIPNet in action: 10 years, 10 stories. Geneva: WHO; 2016.

15. Kickbusch I, Silberschmidt G, Buss P. Global health diplomacy: the need for new perspectives, strategic approaches and skills in global health. Bull World Health Organ. 2007;85(3):230-232. doi:10.2471/BLT.06.039222.

16. Vasconcellos AG, Fonseca EFBP, Morel CM. Revisiting the concept of Innovative Developing Countries (IDCs) for its relevance to health innovation and neglected tropical diseases and for the prevention and control of epidemics. PLoS Negl Trop Dis. 2018;12(7):e0006469. doi:10.1371/journal.pntd.0006469.

17. Certain E, Terry RF, Zicker F. Shaping the research agenda.
PLoS Negl Trop Dis. 2015;9(1):e3350. doi:10.1371/journal. pntd.0003350.

18. ESSENCE on Health Research. WHO website. http://www.who. int/tdr/partnerships/essence/en/.

19. Council of Health Research for Development (COHRED). Framework and guides for system strengthening. http://www. cohred.org/research-innovation-system-strengthening-approach/.

20. Ghaffar A, IJsselmuiden C, Zicker F. Changing mindsets: research capacity strengthening in low- and middle-income countries. WHO website. http://www.who.int/tdr/publications/documents/ changing_mindsets.pdf. Published 2010.

21. Special Programme for Research and Training in Tropical Diseases (TDR). Key enabling factors in effective and sustainable research networks. WHO website. http://www.who.int/tdr/publications/ research-networks/en/. Published 2016.

22. Dean L, Gregorius S, Bates I, Pulford J. Advancing the science of health research capacity strengthening in low-income and middleincome countries: a scoping review of the published literature, 2000-2016. BMJ Open. 2017;7(12):e018718. doi:10.1136/ bmjopen-2017-018718.

23. Peters DH, Tran NT, Adam T. Implementation research in health: a practical guide. Alliance for Health Policy and Systems Research, World Health Organization; 2013. http://www.who.int/alliancehpsr/alliancehpsr_irpguide.pdf.

24. Kaiser K, IJsselmuiden C. From good intentions to Equitable Solutions in Health Research Collaborations - The Research Fairness Initiative (RFI). http://www.internationalhealthpolicies. org/from-good-intentions-to-equitable-solutions-in-healthresearch-collaborations-the-research-fairness-initiative-rfi/. Published 2018 . 